\title{
Inhibitory effect of arazyme on the development of atopic dermatitis-like lesions in BALB/c and Nc/Nga mice
}

\author{
IN SIK KIM ${ }^{1,2}$, NA RAE LEE ${ }^{1}$, SEUNG YEOP BAEK ${ }^{1,2}$, EUN JEONG KIM ${ }^{1,2}$, JUNG SEOK KIM ${ }^{1}$, \\ TAE-SOOK JEONG ${ }^{3}$, DONG-HA SHIN ${ }^{4}$, HO-YONG PARK ${ }^{3}$ and JI-SOOK LEE ${ }^{5}$ \\ ${ }^{1}$ Department of Biomedical Laboratory Science, School of Medicine; ${ }^{2}$ Department of Senior Healthcare, \\ BK21 Plus Program, Graduated School, Eulji University, Daejeon 301-746; ${ }^{3}$ Industrial Bio-material Research Center, \\ Korea Research Institute of Bioscience and Biotechnology, Daejeon 305-806; ${ }^{4}$ Insect Biotech Co., Ltd., Daejeon 305-811; \\ ${ }^{5}$ Department of Clinical Laboratory Science, Wonkwang Health Science University, Iksan 570-750, Republic of Korea
}

Received June 23, 2014; Accepted December 19, 2014

DOI: $10.3892 / \mathrm{mmr} .2015 .3225$

\begin{abstract}
Arazyme is a metalloprotease released by Aranicola proteolyticus that was shown to inhibit cytokine release in $\mathrm{HaCaT}$ and endothelial cells. However, the regulatory effects of arazyme in atopic dermatitis remain to be fully understood. In the present study, the anti-inflammatory effects of arazyme in $\mathrm{BALB} / \mathrm{c}$ and $\mathrm{Nc} / \mathrm{Nga}$ mice induced with 2,4-dinitrochlrobenzene (DNCB) were investigated. BALB/c mice were sensitized with DNCB and were subsequently administered arazyme for 4 weeks either orally, dorsally or orally/dorsally. Arazyme administration significantly reduced epidermal thickening and infiltration of inflammatory cells into the dermis compared with the DNCB group. However, serum immunoglobulin E (IgE) levels were not altered by arazyme treatment. Additionally, the level of secretion of interleukins (IL) $-4,-5$ and -13 in the splenocytes of $\mathrm{BALB} / \mathrm{c}$ mice was elevated following stimulation with concanavalin $\mathrm{A}$, while the increase of IL- 4 and IL-13 was inhibited by arazyme. Administration of arazyme $(25 \mathrm{mg} / \mathrm{kg}$ in phosphate-buffered saline) to $\mathrm{Nc} / \mathrm{Nga}$ mice that had been sensitized with DNCB for 6 weeks reduced the skin severity score compared with that in the DNCB group and inhibited the histological manifestations of atopic dermatitis-like skin lesions. In addition, the serum IgE levels were reduced in the arazyme-treated NC/Nga mice relative to the DNCB group. Collectively, these results indicated that arazyme attenuates the development of atopic dermatitis-like lesions via lowering the levels of IgE and inflammatory cytokines. The results of the present study will aid in the development of effective therapeutic strategies for the treatment of allergic diseases, including atopic dermatitis.
\end{abstract}

Correspondence to: Professor Ji-Sook Lee, Department of Clinical Laboratory Science, Wonkwang Health Science University, 501 Iksandaero, Iksan 570-750, Republic of Korea

E-mail: jslee1216@wu.ac.kr

Key words: arazyme, atopic dermatitis, anti-inflammatory effect, immunoglobulin E

\section{Introduction}

Atopic dermatitis (AD) is a chronic pruritic and inflammatory skin disease that generally occurs in children, and the incidence of $\mathrm{AD}$ is increasing annually. $\mathrm{AD}$ is caused by a variety of genetic and environmental factors and characterized by inflammation and tissue damage in the skin $(1,2)$. Previous studies have reported that $\mathrm{AD}$ is associated with increased expression of immunoglobulin $\mathrm{E}$ ( $\operatorname{IgE}$ ), secretion of $\mathrm{T}$ helper (Th) 2 cytokines and eosinophil count in the serum $(3,4)$. However, the pathogenesis of AD remains to be fully elucidated. As a result, patients with AD are not treated with drugs specific to $\mathrm{AD}$, but are administered with anti-inflammatory or immunosuppressive drugs. Certain drugs used for the long-term treatment of $\mathrm{AD}$ have been reported to cause severe side effects, including immunosuppression and dysfunction of the epidermal barrier $(5,6)$.

Arazyme is an extracellular metalloprotease produced by Aranicola proteolyticus, which is an aerobic Gram negative bacterium isolated from the intestine of the spider Nephila clavata $(7,8)$. A previous study demonstrated that arazyme inhibits the secretion of inflammatory cytokines and increases the expression of skin barrier proteins (9). In addition, arazyme has been reported to suppress the inflammatory response induced by lipopolysaccharides in endothelial cells (10). In the present study, the anti-inflammatory effects of arazyme were investigated in AD-like animal models, BALB/c and Nc/Nga mice.

\section{Materials and methods}

Enzyme purification. Arazyme was purified from extracellular fractions of S. proteamaculan HY-3 (KCTC2390; Korean Collection for Type Culture, Daejeon, Korea) as previously described (8). In brief, extracellular fractions were collected by centrifugation of the Luria-Bertani (LB) culture medium (Sigma-Aldrich Korea, Seoul, Korea) at 5,000 x g for $10 \mathrm{~min}$, or by filtration using a $0.2-\mu \mathrm{m}$ membrane filter (Pall Life Sciences, Port Washington, NY, USA). Chromatography was subsequently performed on a DEAE-cellulose column (GE Healthcare Life Sciences, Little Chalfont, UK) 
equilibrated with $50 \mathrm{mM}$ potassium phosphate buffer ( $\mathrm{pH}$ 7.6; Sigma-Aldrich Korea). Bound proteins were then eluted with a 0.1-0.5 M sodium chloride (Sigma-Aldrich Korea) gradient at a flow rate of $400 \mathrm{ml} / \mathrm{h}$ and following this, each fraction was concentrated using a $10-\mathrm{kD}$ cassette membrane (Pall Life Sciences). The protein solution was loaded onto a Sephadex G-75 column (GE Healthcare Life Sciences) equilibrated with $50 \mathrm{mM}$ potassium phosphate buffer $(\mathrm{pH} \mathrm{7.8)}$ at a flow rate of $20 \mathrm{ml} / \mathrm{h}$ and fractions with proteolytic activity were concentrated with a $10-\mathrm{kD}$ cassette membrane and stored at $-20^{\circ} \mathrm{C}$. Proteolytic activity was determined spectrophotometrically by measuring absorbance at $405 \mathrm{~nm}$ (SpectroQuest UV-2800, cat. no. S90424; Thermo Fisher Scientific, Inc., Waltham, MA USA), as previously described (8).

Induction of allergic dermatitis in BALB/C and Nc/Nga mice. A total of 40 five-week-old female BALB/c mice (weight, 17-19 g) and $30 \mathrm{NC} / \mathrm{Nga}$ mice (weight, 19-21 g) were purchased from Japan SLC, Inc. (Hamamatsu, Japan) and acclimated for one week prior to the start of the experiments. Animals were housed in an air-conditioned animal unit at $23 \pm 2^{\circ} \mathrm{C}$ and a humidity of $50 \pm 10 \%$. Mice were provided with solid feed (Rodfeed; Daehan Biolink Co., Ltd., Eumsung, Korea). A schematic diagram of the experimental procedure is provided in Fig. 1. Induction of AD was performed with 2,4-dinitrochlorobenzene (DNCB; Sigma-Aldrich, St. Louis, MO, USA) in BALB/c and NC/Nga mice. In brief, $1 \%$ DNCB was dissolved in an acetone-olive oil mixture (acetone/olive oil, 3:1; Sigma-Aldrich Korea). The dorsal hair of the mice was removed with an electric razor and no skin damage (e.g. chafed skin or hemorrhage) was observed. A total of $0.15 \mathrm{ml} \mathrm{1 \%} \mathrm{DNCB} \mathrm{solution} \mathrm{was} \mathrm{applied} \mathrm{to} \mathrm{the} \mathrm{same}$ area of dorsal skin. Following sensitization with $1 \%$ DNCB, the $\mathrm{BALB} / \mathrm{c}$ mice were dorsally treated with $0.3 \% \mathrm{DNCB}$ three times/week for 4 weeks, then once/week for 4 weeks. $\mathrm{Nc} / \mathrm{Nga}$ mice were treated with $0.3 \%$ DNCB three times/week for 4 weeks and then twice per week for 6 weeks. The protocol for the care and treatment of the mice was approved by the Institutional Animal Care and Use Committee of Eulji University (Daejeon, Republic of Korea).

Arazyme administration. BALB/c mice were divided into the following eight groups ( $n=5$ in each group): Untreated; DNCB; oral arazyme (10 mg/kg); $25 \mathrm{mg} / \mathrm{kg}$ dorsal arazyme; combined treatment with $5 \mathrm{mg} / \mathrm{kg}$ oral and $12.5 \mathrm{mg} / \mathrm{kg}$ dorsal arazyme; $5 \mathrm{mg} / \mathrm{kg}$ oral dexamethasone; $5 \mathrm{mg} / \mathrm{kg}$ dorsal dexamethasone; and combined treatment with $2.5 \mathrm{mg} / \mathrm{kg}$ oral and $2.5 \mathrm{mg} / \mathrm{kg}$ dorsal dexamethasone, which were all purchased from Sigma-Aldrich Korea. Nc/Nga mice were divided into the following six groups ( $\mathrm{n}=5$ in each group): Untreated; DNCB; $25 \mathrm{mg} / \mathrm{kg}$ arazyme; $50 \mathrm{mg} / \mathrm{kg}$ arazyme; $125 \mathrm{mg} / \mathrm{kg}$ arazyme; $5 \mathrm{mg} / \mathrm{kg}$ dexamethasone. The DNCB, arazyme and dexamethasone groups were dorsally administered with $1 \%$ DNCB and subsequently dorsally treated with $0.3 \%$ DNCB. The DNCB, arazyme and dexamethasone groups were treated with phosphate-buffered saline (PBS; Sigma-Aldrich Korea), arazyme and dexamethasone via gastric inoculation with a mouse-feeding needle (Cadence, Inc., Staunton, VA, USA) and/or application to the same area of the dorsal skin. The untreated group was treated with PBS without administration of DNCB, arazyme or dexamethasone.
A $\mathrm{BALB} / \mathrm{c} \mathrm{mice}$

Ara administration

Oral (10 mg/kg), Dorsal $(25 \mathrm{mg} / \mathrm{kg})$ or

Oral (5 mg/kg)/dorsal (12.5 mg/kg)

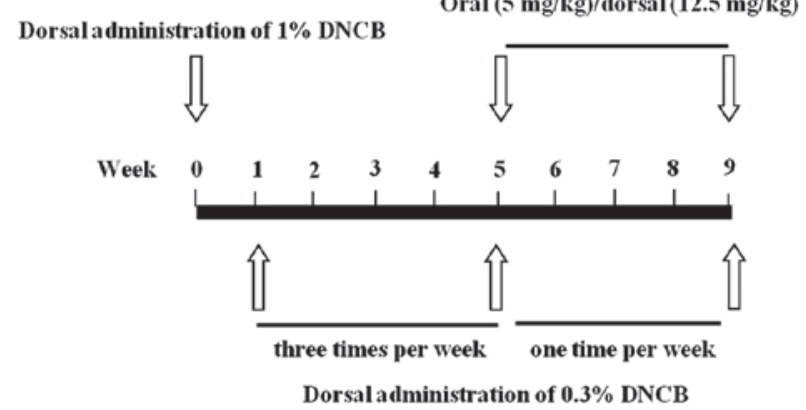

B

Nc/Nga mice

Oral a dministration of Ara

( $25 \mathrm{mg} / \mathrm{kg}, 50 \mathrm{mg} / \mathrm{kg}$ or $125 \mathrm{mg} / \mathrm{kg}$ )

Dorsal administration of $1 \%$ DNCB

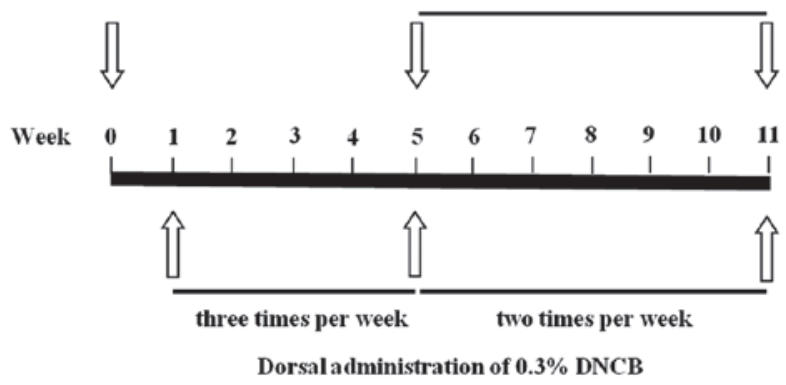

Figure 1. Experimental schedule for the induction of AD lesions. AD was induced by DNCB in (A) BALB/c and (B) NC/Nga mice. Following initial sensitization with $1 \% \mathrm{DNCB}$, the BALB/c mice were dorsally treated with $0.3 \%$ DNCB three times/week for 4 weeks and then once/week for 4 weeks. $\mathrm{Nc} / \mathrm{Nga}$ mice were treated with $0.3 \% \mathrm{DNCB}$ three times/week for 4 weeks and then twice/week for 6 weeks. The BALB/c and Nc/Nga mice were treated orally, dorsally or orally/dorsally with Ara. AD, atopic dermatitis; DNCB, 2,4-dinitrochlorobenzene; Ara, arazyme.

Histological analysis. Subsequent to sacrifice of the mice by $\mathrm{CO}_{2}$ asphyxiation, the dorsal skin was removed, fixed in Carnoy's solution (Sigma-Aldrich Korea), embedded in paraffin (Sigma-Aldrich Korea) and sectioned (5 $\mu$ m-thick). The sections were then stained with hematoxylin-eosin solution (Sigma-Aldrich Korea) and subsequently examined by light microscopy (Leica Microsystems, Wetzlar, Germany) for histological evaluation. Specifically, the epidermis was evaluated for hypertrophy and infiltration by inflammatory cells, while the dermis was evaluated for infiltration by inflammatory cells.

Measurement of serum IgE. Blood was collected from the tail of the mice every week. The serum was obtained by centrifugation and then stored at $-70^{\circ} \mathrm{C}$ until required. Total IgE levels in the serum were measured using sandwich ELISA kits (BD Biosciences, San Jose, CA, USA) according to the manufacturer's instructions.

Splenocyte preparation. The BALB/c mice were sacrificed and subsequently their spleens were removed under aseptic conditions. Splenocytes were then isolated from the spleens as previously described (11), after which the red blood cells were 
$\mathbf{A}$

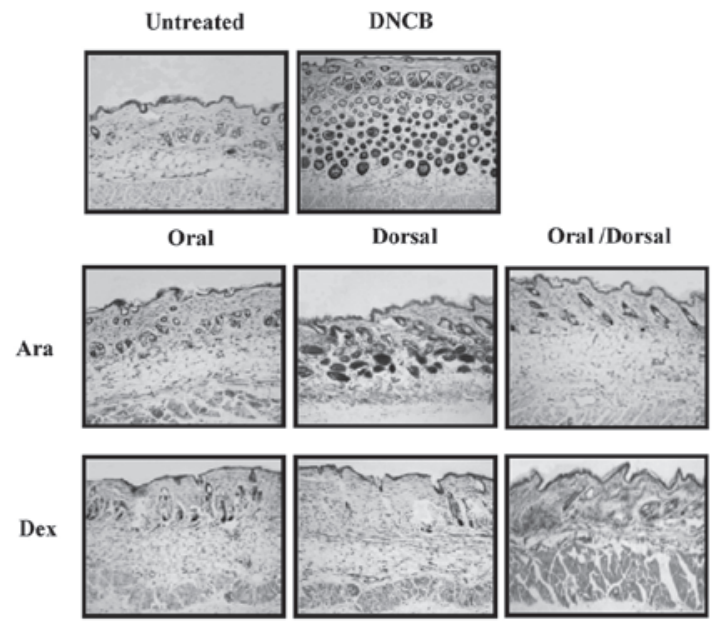

B

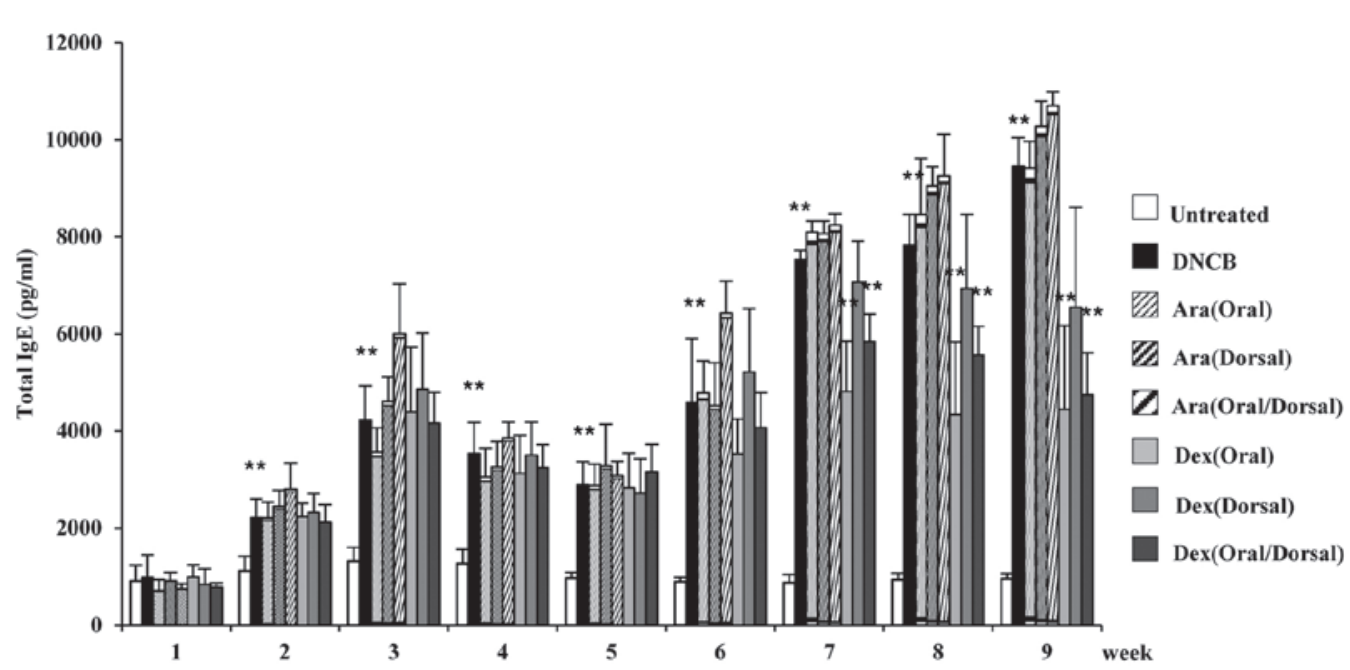

C

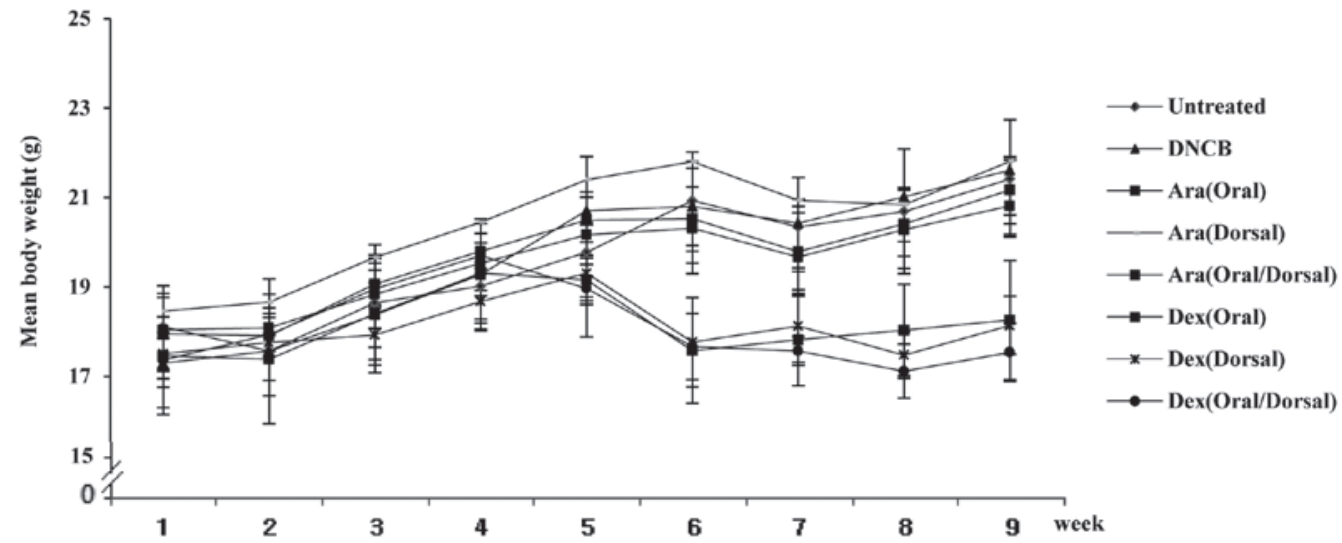

Figure 2. Arazyme reduces the aggravation of atopic-like skin lesions, but has no effect on the serum levels of IgE in DNCB-induced BALB/c mice. Mice were divided into the following four groups: Untreated, DNCB, Ara and Dex. (A) For histological analysis, the dorsal skin was fixed and embedded in paraffin, sectioned, stained with hematoxylin and eosin solution and examined by light microscopy (magnification, x200). (B) Serum was collected from the blood of the NC/Nga mice weekly and total IgE levels in the serum were measured using sandwich ELISA kits. (C) The mean body weight of mice was measured using an electric scale. Values are presented as the mean \pm standard deviation. ${ }^{* *} \mathrm{P}<0.01$, untreated vs. DNCB group and DNCB vs. drug-treated group. IgE, immunoglobulin E; DNCB, 2,4-dinitrochlorobenzene; Ara, arazyme; Dex, dexamethasone.

hemolyzed using red blood cell lysis solution (Sigma-Aldrich). Splenocytes were seeded in a 24-well plate at a concentration of $5 \times 10^{6}$ cells $/ \mathrm{ml}$ in RPMI-1640 medium with $1 \%$ penicillin-streptomycin and 10\% fetal bovine serum (Gibco-BRL, Grand Island, NY, USA).

ELISA. Splenocytes were pretreated in the absence or presence of arazyme and then stimulated with $1 \mu \mathrm{g} / \mathrm{ml}$ concanavalin A
(Sigma-Aldrich Korea) for $24 \mathrm{~h}$. The cell supernatants were collected and the concentrations of interleukin (IL)-4, IL-5 and IL-13 were measured in the supernatant by a sandwich ELISA [OptEIA ${ }^{\mathrm{TM}}$ Human IL-4 and IL-5 sets; BD Biosciences; and Human IL-13 DuoSet kit, R\&D Systems, Inc. (Minneapolis, MN, USA)] according to the manufacturer's instructions. The concentration of each protein was calculated from the standard curves. 
Evaluation of skin severity. The severity of dermatitis was assessed macroscopically in a blinded experiment. The four indicators of skin lesions were: i) Erythema/hemorrhage, ii) edema/swelling, iii) excoriation/erosion and iv) dryness. Scoring was performed as follows: 0 (no symptoms), 1 (mild), 2 (moderate) and 3 (severe) (12).

Measurement of alanine aminotransferase (ALT) and aspartate aminotransferase (AST). The concentrations of ALT and AST were measured using the Reitman-Frankel method (13) in the serum of BALB/c mice using ALT and AST assay kits (Asan Pharm Co., Seoul, Korea) according to the manufacturer's instructions.

Statistical analysis. Values are expressed as the mean \pm standard deviation. Data were analyzed using Student's t-test using SPSS software, version 10.0 (SPSS Inc., Chicago, IL, USA). $\mathrm{P}<0.05$ was considered to indicate a statistically significant difference.

\section{Results}

Arazyme reduces the aggravation of atopic-like skin lesions but has no effect on the serum IgE levels in DNCB-induced $B A L B / c$ mice. The therapeutic effects of arazyme were investigated in mice with DNCB-induced dermatitis by histological evaluation. Histological analysis of the skin of mice in the untreated group revealed that the tissue was normal, whereas mice in the DNCB group exhibited epidermal hypertrophy, hyperkeratosis of the epidermis and infiltration of inflammatory cells (Fig. 2A). Oral and oral/dorsal administration of arazyme markedly ameliorated the histopathological alterations as compared with those in the dexamethasone group, while dorsal administration of arazyme resulted in a small reduction in these alterations. Mice in the group administered oral/dorsal dexamethasone exhibited atrophy of the skin. Since $\operatorname{IgE}$ is known to act as an important pathogenic factor in $\mathrm{AD}(3,4)$, it was investigated whether the anti-inhibitory effects of arazyme were involved in the alteration of $\operatorname{IgE}$ production. Although the serum levels of IgE in the DNCB group were markedly upregulated compared with those in the untreated group, arazyme was not observed to effectively reduce these elevated IgE levels (Fig. 2B). The body weight of mice in the arazyme group was comparable to that of mice in the untreated and DNCB groups (Fig. 2C), while a reduction in body weight was observed in the dexamethasone group after 5 weeks.

Arazyme suppresses cytokine levels in mouse splenocytes. Inflammatory cytokines, particularly Th2 cytokines, serve essential roles in allergic diseases such as $\mathrm{AD}(3,4)$; thus, the effects of arazyme on cytokine production were investigated. Splenocytes isolated from the spleens of BALB/c mice were treated with arazyme for $1 \mathrm{~h}$ and subsequently with concanavalin A for $24 \mathrm{~h}$. The synthesis of IL-4, IL-5 and IL-13 was observed to increase in the supernatant of splenocytes following stimulation with concanavalin A for 24 and $48 \mathrm{~h}$ (Fig. 3). Pretreatment with arazyme inhibited the increased secretion of IL-4 and IL-13. IL-5 release remained unchanged in the arazyme-treated splenocytes.
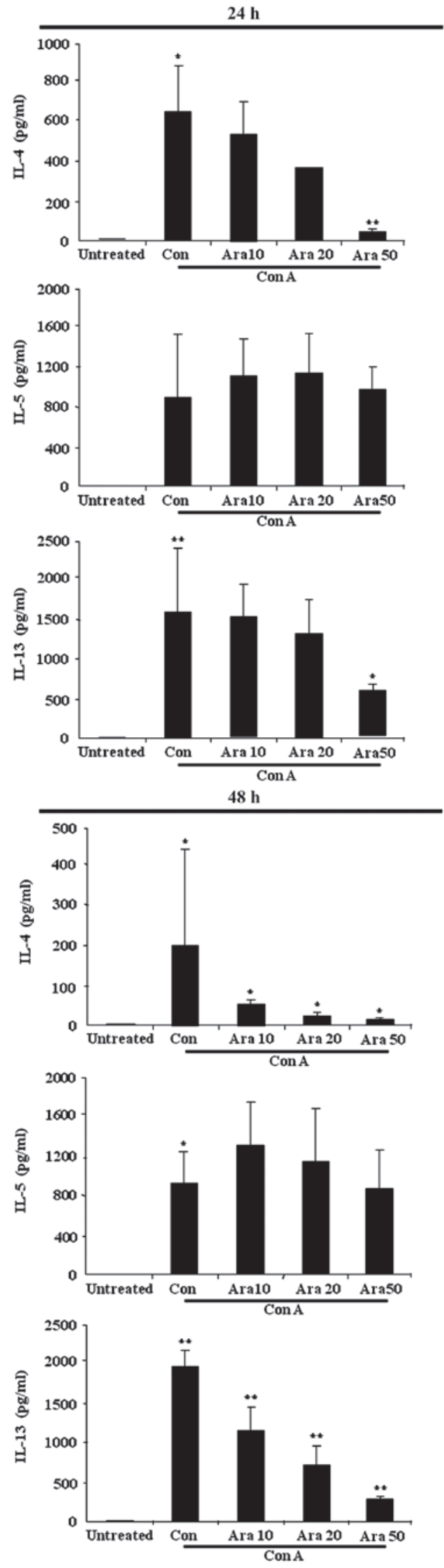

Figure 3. Arazyme suppresses cytokine synthesis in BALB/c mouse splenocytes pretreated with Ara at the indicated concentrations (Ara $10,10 \mathrm{mg} / \mathrm{ml}$; Ara $20,20 \mathrm{mg} / \mathrm{ml}$; Ara 50,50 mg/ml) for $1 \mathrm{~h}$. The cytokines were analyzed by ELISA. Values are presented as the mean \pm standard deviation of three independent experiments. ${ }^{*} \mathrm{P}<0.05$ and ${ }^{* *} \mathrm{P}<0.01$, untreated vs. control group and control vs. arazyme-treated group. Ara, arazyme; Con, control; Con A, concanavalin A; IL, interleukin. 
A
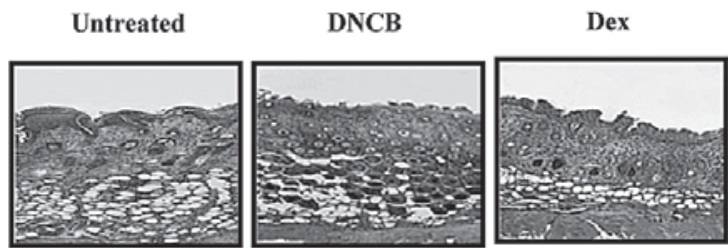

Ara 25

Ara 50

Ara 125
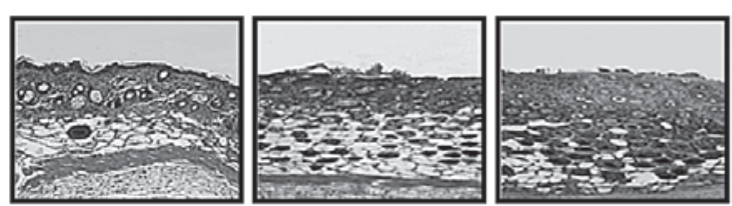

B

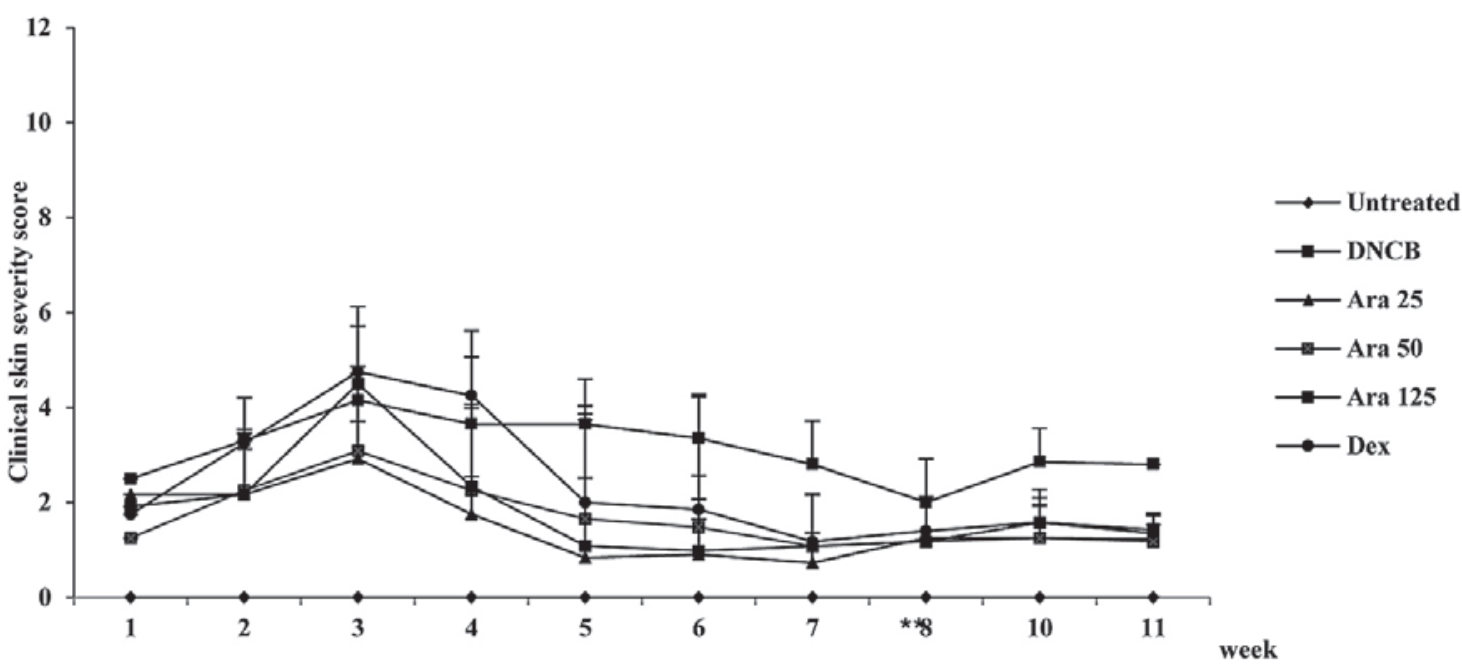

C

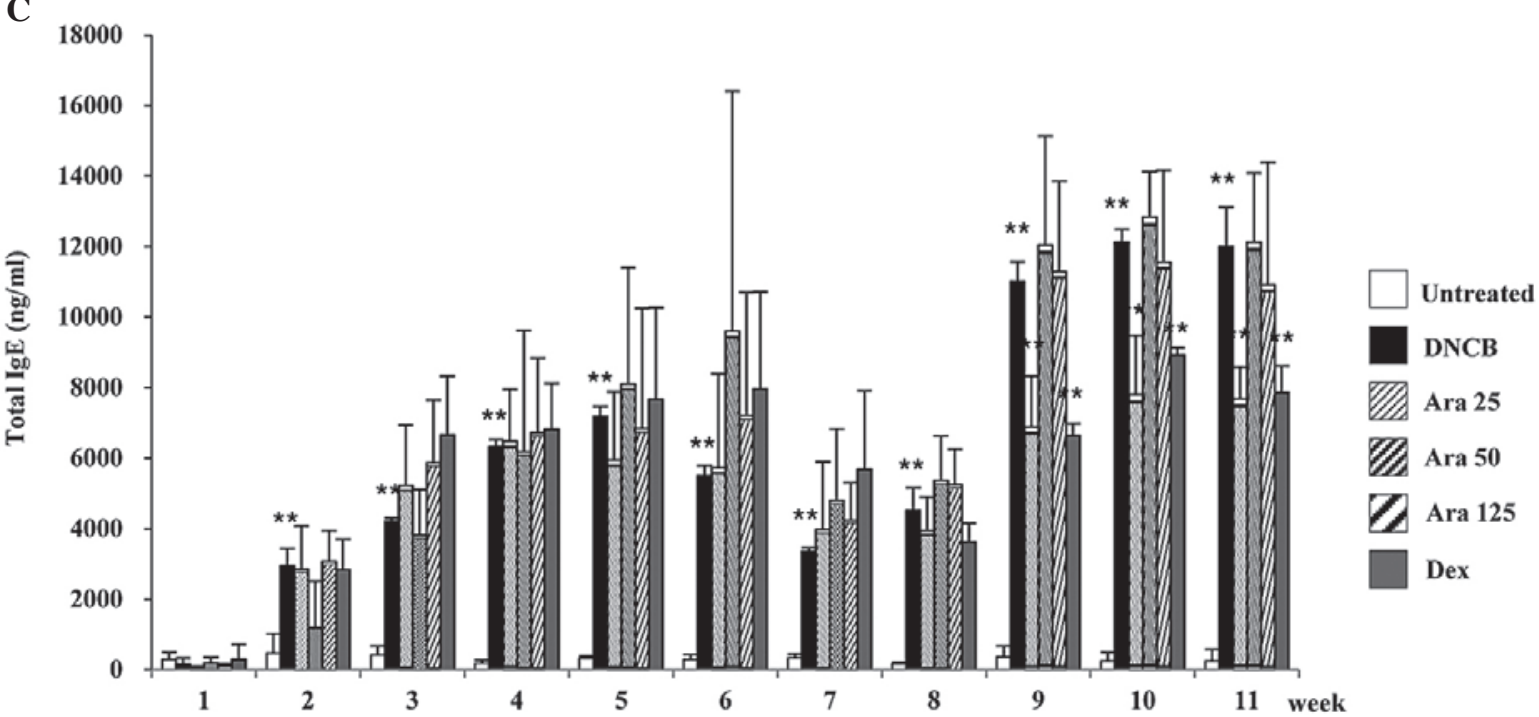

Figure 4. Arazyme suppresses the severity of dermatitis and IgE levels in DNCB-induced AD using NC/Nga mice. The mice were divided into the following four groups: Untreated, DNCB, Ara and Dex. The DNCB, Ara and Dex groups were dorsally administered with $1 \%$ DNCB and then dorsally treated with $0.3 \%$ DNCB. Ara was administered orally at the following concentrations: Ara 25, $25 \mathrm{mg} / \mathrm{kg}$; Ara 50, $50 \mathrm{mg} / \mathrm{kg} ;$ Ara $125,125 \mathrm{mg} / \mathrm{kg}$. Dex was administerd orally at $5 \mathrm{mg} / \mathrm{kg}$. (A) For histological analysis, the dorsal skin was fixed and embedded in paraffin, sectioned, stained with hematoxylin and eosin solution and examined by light microscopy (magnification, x200). (B) The severity of dermatitis was assessed macroscopically in a blinded experiment and (C) total IgE levels in the serum were measured using sandwich ELISA kits. Values are presented as the mean \pm standard deviation. ${ }^{* *} \mathrm{P}<0.01$, untreated vs. DNCB group and DNCB vs. drug-treated group. Ara, arazyme; IgE, immunoglobulin E; DNCB, 2,4-dinitrochlorobenzene; AD, atopic dermatitis; Dex, dexamethasone.

Arazyme suppresses the severity of dermatitis and IgE levels in DNCB-induced AD using NC/Nga mice. As the oral treatment of arazyme proved effective at inhibiting histopathological features in AD-like BALB/c mice, the effects of oral administration of arazyme on $\mathrm{Nc} / \mathrm{Nga}$ mice were investigated as an additional AD-like model. The DNCB group exhibited epidermal hyperplasia, hyperkeratosis and inflammation (Fig. 4A). Oral administration of arazyme resulted in suppression of the histological phenomena associated with $\mathrm{AD}$ at low concentrations $(25 \mathrm{mg} / \mathrm{kg})$, while treatment with high concentrations (50 and $100 \mathrm{mg} / \mathrm{kg}$ ) of arazyme resulted in either a weak or absent effect. The severity of dermatitis 
A

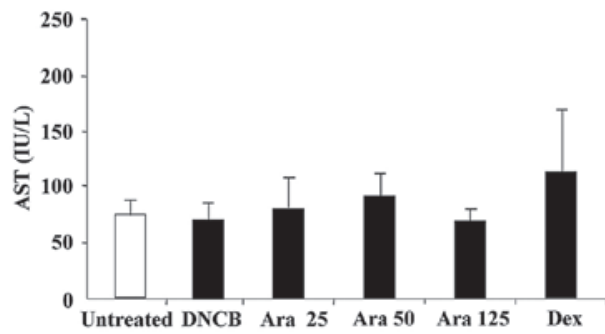

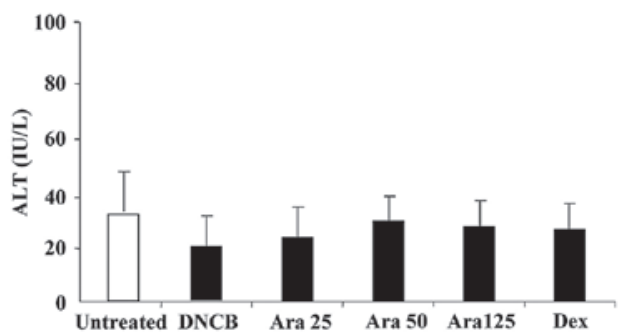

B

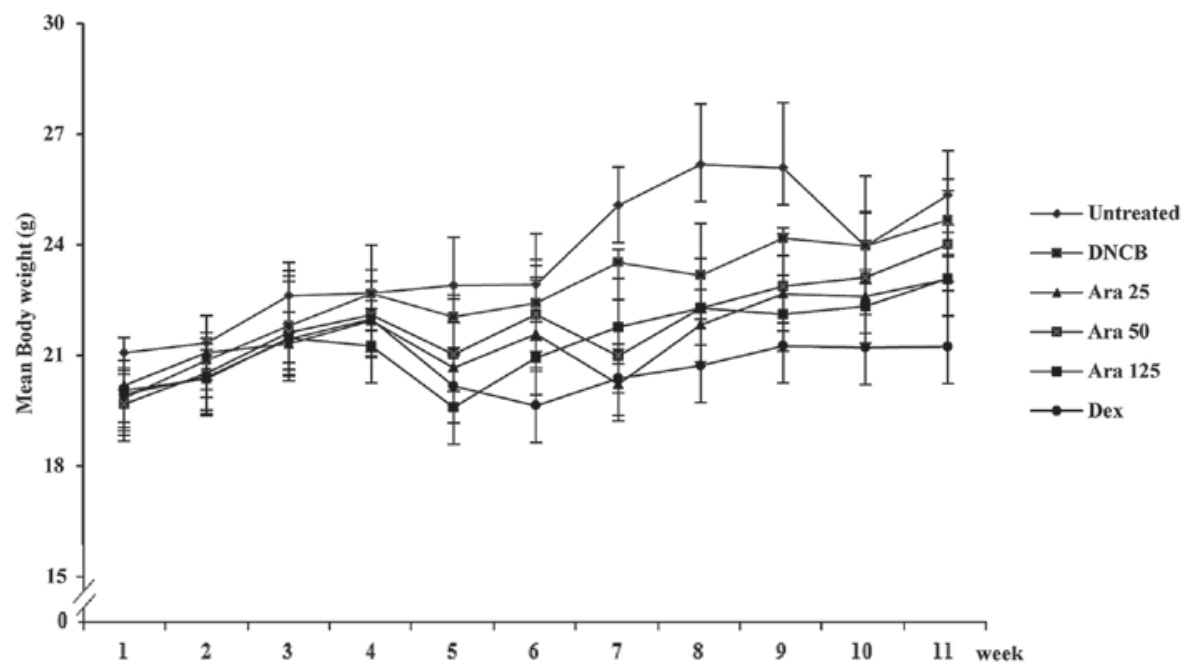

Figure 5. Effects of Arazyme on transaminase levels and body weight of mice. (A) AST and ALT levels in serum were measured by the Reitman-Frankel method. (B) The mean body weight of the mice was measured using an electric scale. Values are presented as the mean \pm standard deviation of three independent experiments. AST, aspartate aminotransferase; ALT, alanine aminotransferase; DNCB, 2,4-dinitrochlrobenzene; Ara, arazyme; Dex, dexamethasone.

was evaluated every week. Clinical signs and symptoms of AD developed subsequent to dorsal treatment with DNCB and these symptoms were observed to worsen with time following the initial treatment. As demonstrated in Fig. 4B, the DNCB group exhibited thick skin with severe erythema, hemorrhage, edema, erosion and excoriation. However, oral application of arazyme at low concentrations inhibited the development of these skin conditions. In addition, $25 \mathrm{mg} / \mathrm{kg}$ arazyme was observed to significantly reduce $\left({ }^{* *} \mathrm{P}<0.01\right)$ the elevated $\mathrm{IgE}$ levels in the serum at weeks 9,10 and 11 and the suppressive effect of arazyme was comparable to that produced by treatment with dexamethasone (Fig. 4C). However, high concentrations of arazyme had no inhibitory effect on the alterations in IgE levels. To confirm the cytotoxicity of arazyme, the alterations in body weight, ALT and AST levels in the serum were investigated. The levels of ALT and AST were unchanged by administration of arazyme (Fig. 5A). Body weight was only identified to be altered in the dexamethasone group (Fig. 5B).

\section{Discussion}

Arazyme isolated from Aranicola proteolyticus has been previously observed to serve a protective role in hepatic injury $(8,14)$. Arazyme has been identified to exert an inhibitory effect on the inflammatory response in human umbilical vein endothelial cells induced by lipopolysaccharides and on cytokine expression in inflammatory cells; furthermore, an arazyme-induced upregulation of skin barrier protein levels has been observed in keratinocytes $(9,10)$. Thus, the present study investigated whether arazyme alleviates the clinical features of AD. Mouse models of AD are commonly classified into three groups: i) Those that require epicutaneous administration of sensitizers, ii) skin gene-defective transgenic models and iii) models involving the spontaneous development of AD $(4,15)$. In the present study, BALB/c and Nc/Nga mice were selected for use as AD-like mouse models and DNCB was employed as the sensitizer. In BALB/c mice, arazyme was identified to inhibit the histological features associated with AD. Furthermore, oral administration of arazyme was observed to be more effective than dorsal treatment. Arazyme additionally suppressed the histopathological appearance and clinical severity score in $\mathrm{Nc} / \mathrm{Nga}$ mice. In contrast to BALB/c mice, arazyme lowered the serum $\mathrm{IgE}$ levels in $\mathrm{Nc} / \mathrm{Nga}$ mice. This difference may have been due to the use of different mouse species. It is well known that immunological responses of humans and mice are distinctly different; therefore, caution should be taken prior to conducting a clinical trial. In the present study, the effects of arazyme on the severity of AD were not dose-dependent. To determine an appropriate concentration of arazyme and overcome the different results obtained using different animal models, future studies employing another model such as a mite-induced or transgenic model would be beneficial.

The pathogenesis and progression of AD is caused by various factors associated with immune dysregulation or hypersensitivity and the balance of T helper (Th) 1/Th2 cytokines (16-18). IL-4 results in the differentiation of naive Th0 cells to Th2 cells and induces chronic inflammation (15). Additionally, it was recently reported that IL-4 regulates 
alternative macrophage activation (19). The function of IL-13 is similar to that of IL-4 (15). In the present study, arazyme suppressed the secretion of IL-4 and IL-13, but had no effect on that of IL-5. Inhibition of IL-4 and IL-13 may be correlated with alleviation of histopathological features associated with AD. Although increased circulation of IgE in AD is positively correlated to IL-4 and IL-13 expression in CD4+ T cells (20), arazyme was not observed to be effective at reducing the serum IgE levels in $\mathrm{AD}-$ like $\mathrm{BALB} / \mathrm{c}$ mice. In contrast to the effects of arazyme on $\mathrm{IgE}$ expression in $\mathrm{BALB} / \mathrm{c}$ mice, arazyme downregulated the serum levels of $\operatorname{IgE}$ and inhibited histological inflammation in $\mathrm{Nc} / \mathrm{Nga}$ mice.

To elucidate this difference, future studies are required in order to determine how arazyme inhibits the pathophysiological mechanisms of AD. Arazyme induces anti-oxidant signaling in addition to the inhibition of Th2 cytokine release $(9,14)$. Additionally, arazyme induces expression of filaggrin and involucrin included in skin barrier proteins (9). As arazyme is a metalloprotease, it may exert its function via a protease-activated receptor. Further studies are required to examine these complex inhibitory mechanisms in greater detail.

In conclusion, arazyme alleviated the clinical features in $\mathrm{BALB} / \mathrm{c}$ and $\mathrm{Nc} / \mathrm{Nga}$ models of $\mathrm{AD}$ and diminished the synthesis of Th2 cytokines, including IL-4 and IL-13, in addition to the serum IgE levels. These observations indicated that arazyme may be valuable for the treatment of allergic diseases such as AD.

\section{Acknowledgements}

This research was supported by a grant from the Korea Research Institute of Bioscience \& Biotechnology Research Initiative Program.

\section{References}

1. Bieber T: Atopic dermatitis. N Engl J Med 358: 1483-1494, 2008

2. Barnes KC: An update on the genetics of atopic dermatitis: scratching the surface in 2009. J Allergy Clin Immunol 125: 16-29, 2010.

3. Habu Y, Seki S, Takayama E, Ohkawa T, Koike Y, Ami K, Majima $\mathrm{T}$ and Hiraide $\mathrm{H}$ : The mechanism of a defective IFN-gamma response to bacterial toxins in an atopic dermatitis model, NC/Nga mice, and the therapeutic effect of IFN-gamma, IL-12, or IL-18 on dermatitis. J Immunol 166: 5439-5447, 2001.

4. Jin H, He R, Oyoshi M and Geha RS: Animal models of atopic dermatitis. J Invest Dermatol 129: 31-40, 2009.
5. Shiohara T, Hayakawa J and Mizukawa Y: Animal models for atopic dermatitis: are they relevant to human disease? J Dermatol Sci 36: 1-9, 2004.

6. Berke R, Singh A and Guralnick M: Atopic dermatitis: an overview. Am Fam Physician 86: 35-42, 2012.

7. Bersanetti PA, Park HY, Bae KS, Son KH, Shin DH, Hirata IY, Juliano MA, Carmona AK and Juliano L: Characterization of arazyme, an exocellular metalloprotease isolated from Serratia proteamaculans culture medium. Enzyme Microb Technol 37: 574-581, 2005.

8. Kwak J, Lee K, Shin DH, Maeng JS, Park DS, Oh HW, Son KH, Bae KS and Park HY: Biochemical and genetic characterization of arazyme, an extracellular metalloprotease produced from Serratia proteamaculans HY-3. J Microbiol Biotechnol 17: 761-768, 2007.

9. Kim IS, Kim MJ, Shin DH, Son KH, Park HY and Lee JS: Arazyme inhibits cytokine expression and upregulates skin barrier protein expression. Mol Med Rep 8: 551-556, 2013.

10. Kim IS, Yang EJ, Shin DH, Son KH, Park HY and Lee JS: Effect of arazyme on the lipopolysaccharide-induced inflammatory response in human endothelial cells. Mol Med Rep 10: 1025-1029, 2014.

11. Lee JS, Kim IS, Ryu JS, Kim JH, Kim JS, Kim DH and Yun CY: The inhibitory effect of Duchesnea chrysantha extract on the development of atopic dermatitis-like lesions by regulating IgE and cytokine production in Nc/Nga mice. Phytother Res 26: 284-290, 2012.

12. Kim IS, Kim DH, Yun CY and Lee JS: A (S)-(+)-decursin derivative, (S)-(+)-3-(3,4-dihydroxy-phenyl)-acrylic acid 2,2-dimethyl-8-oxo-3,4-dihydro-2H,8H-pyrano[3,2-g]-chromen -3-yl-ester, attenuates the development of atopic dermatitis-like lesions in NC/Nga mice. Mol Biol Rep 40: 2541-2548, 2013.

13. Witter RF and Grubbs LM: An evaluation of the Reitman-Frankel method for the determination of serum glutamic oxalacetic transaminase. Clin Chim Acta 13: 524-527, 1966.

14. Park JK, Jeong DH, Park HY, Son KH, Shin DH, Do SH, Yang HJ, Yuan DW, Hong IH, Goo MJ, Lee HR, Ki MR, Ishigami A and Jeong KS: Hepatoprotective effect of Arazyme on CCl4-induced acute hepatic injury in SMP30 knock-out mice. Toxicology 246: 132-142, 2008.

15. Tanaka A, Amagai Y, Oida K and Matsuda H: Recent findings in mouse models for human atopic dermatitis. Exp Anim 61: 77-84, 2012.

16. Romagnani S: Lymphokine production by human $\mathrm{T}$ cells in disease states. Annu Rev Immunol 12: 227-257, 1994.

17. Suto H, Matsuda H, Mitsuishi K, Hira K, Uchida T, Unno T, Ogawa H and Ra C: NC/Nga mice: a mouse model for atopic dermatitis. Int Arch Allergy Immunol 120 (Suppl 1): 70-75, 1999.

18. Yang EJ, Lee JS, Yun CY, Kim JH, Kim JS, Kim DH and Kim IS: Inhibitory effects of Duchesnea chrysantha extract on ovalbumin-induced lung inflammation in a mouse model of asthma. J Ethnopharmacol 118: 102-107, 2008.

19. Luzina IG, Keegan AD, Heller NM, Rook GA, Shea-Donohue T and Atamas SP: Regulation of inflammation by interleukin-4: a review of "alternatives". J Leukoc Biol 92: 753-764, 2012.

20. Yamanaka K and Mizutani H: The role of cytokines/chemokines in the pathogenesis of atopic dermatitis. Curr Probl Dermatol 41: 80-92, 2011. 